\title{
Enhanced Vision for All-Weather Operations under NextGen
}

\author{
Randall E. Bailey, ${ }^{*}$ Lynda J. Kramer, and Steven P. Williams \\ NASA Langley Research Center, Mail Stop 152, Hampton, VA 23681
}

\begin{abstract}
Recent research in Synthetic/Enhanced Vision technology is analyzed with respect to existing Category II/III performance and certification guidance. The goal is to start the development of performance-based vision systems technology requirements to support future all-weather operations and the NextGen goal of Equivalent Visual Operations. This work shows that existing criteria to operate in Category III weather and visibility are not directly applicable since, unlike today, the primary reference for maneuvering the airplane is based on what the pilot sees visually through the "vision system." New criteria are consequently needed. Several possible criteria are discussed, but more importantly, the factors associated with landing system performance using automatic and manual landings are delineated.
\end{abstract}

Keywords: Synthetic Vision, Enhanced Vision, Enhanced Flight Vision System, Head-Up Display, Aviation Safety, Flight Deck Systems, All Weather Operations

\section{INTRODUCTION}

The U.S. air transportation system is undergoing a transformation to accommodate a projected threefold increase in air operations by 2025. ${ }^{1}$ One of the key capabilities envisioned to achieve this Next Generation Air Transportation System (NextGen) is the concept of equivalent visual operations (EVO). EVO implies the capability to achieve or even improve on the safety of current-day Visual Flight Rules (VFR) operations, maintain the operational tempos of VFR, and perhaps even retain VFR procedures - all independent of the actual weather and visibility conditions.

One significant challenge to the EVO concept objective is the definition of required equipage on the aircraft and on the airport. With today's equipment and regulations, significant investment is required in on-board equipment for navigation, surveillance, and flight control and on the airport for precision guidance systems and approach lighting systems for "all-weather" landing capability. The levels of equipment redundancy, capability, maintenance, and accuracy dramatically increase as landing visibility minima decrease. EVO implies "Category III" operational capability to all runway thresholds. Synthetic Vision (SV) and Enhanced Vision (EV) offer a means of providing this capability without significant airport infrastructure investment.

The Integrated Intelligent Flight Deck (IIFD) project, ${ }^{2}$ under NASA's Aviation Safety Program (AvSP), is investigating the use of synthetic and enhanced vision $(\mathrm{S} / \mathrm{EV})$ as enabling technologies to meet the challenges of EVO, creating a virtual visual flight environment for the flight crew, independent of the outside weather and visibility conditions. In this paper, recent research in S/EV technology is analyzed with respect to existing Cat II/III performance and certification guidance to identify how S/EV technology may support future all-weather operations and the NextGen goal of EVO.

\section{BACKGROUND}

$\mathrm{SV}$ is a computer-generated image of the external scene topography, generated from aircraft attitude, high-precision navigation, and data of the terrain, obstacles, cultural features, and other required flight information. EV is an electronic means to provide a display (typically on a head-up display, or HUD) of the external scene by use of an imaging sensor, such as a Forward-Looking InfraRed (FLIR) or millimeter wave radar. Both SV and EV are "vision-based" technologies intended to create, supplement, or enhance the natural vision of the pilot.

NASA and others have developed and shown SV technologies to provide significant improvements in terrain awareness and reductions for the potential of Controlled-Flight-Into-Terrain incidents/accidents, ${ }^{3-5}$ improvements in flight technical error to meet Required Navigation Performance criteria, ${ }^{6-7}$ and improvements in situation awareness 
(SA) without concomitant increases in workload compared to current generation cockpit technologies ${ }^{8-12}$ As such, SV is emerging as "standard equipage" for Part 23 and Part 25 business and general aviation aircraft flight decks even though, to date, no "operational credit" is obtained by SV equipage.

EV capability on a HUD using FLIR sensor technology has also carved out a significant share of the business aircraft market. EV provides many of the same operational benefits as SV technology, but it uses a direct view of the external environment, independent of the aircraft navigation solution or database. These differences, in part, enable operational credit by use of an approved EV. In 2004, Chapter 14 of the Code of Federal Regulations (CFR) Section $\$ 91.175$ was amended such that operators conducting straight-in instrument approach procedures (in other than Category II or Category III operations) may now operate below the published Decision Altitude (DA), Decision Height (DH) or Minimum Descent Altitude (MDA) when using an approved Enhanced Flight Vision System (EFVS) shown on the pilot's HUD. (EFVS is the terminology adopted by the FAA to indicate the operational application of an Enhanced Vision System.)

Enhanced flight visibility is defined in the Federal Aviation Regulations (FARs) as "the average forward horizontal distance, from the cockpit of an aircraft in flight, at which prominent topographical objects may be clearly distinguished and identified by day or night by a pilot using an enhanced flight vision system." The concept adopted under the revisions to $\$ 91.175$ of the FARs is that an EFVS, providing enhanced flight visibility, can be used in lieu of the required natural vision from the DA/DH/MDA to $100 \mathrm{ft}$ height above the touchdown zone elevation (TDZE). Minimum aviation system performance standards are now available (RTCA DO-315 $5^{13}$ ) and FAA Advisory Circulars (ACs) are emerging which provide guidance for SV and EV technologies with these operational capabilities.

The emerging challenge for NextGen - and the subject of NASA research - is to develop performance-based standards for SV and EV technologies that go beyond these initial steps toward EVO. The first part of this challenge is the development of performance-based standards for all weather approach and landing.

In this context, a "vision system," derived from Synthetic and/or Enhanced Vision equipment, is defined for generality. The "vision system" (VS) is an electronic means of displaying visual flight references (terrain, obstacles, and operations-critical navigational and situational references) on electronic cockpit display(s) for the flight crew, integrated with conformal symbology providing important situation, guidance, and/or command information as necessary and/or appropriate to enable all weather approach and landing operations.

Several points of emphasis are important within this concept:

- The term VS refers to a system, regardless of source or technology, providing an electronic means of continuous visual-like information for the pilot/flight crew. Under current FAA regulation, only EV technology is permitted, but in future operations, this distinction may not be appropriate.

- A critical component of the system performance is the integration of the "visual-like" imagery with symbology. Under the current EFVS requirement, the FLIR imagery is integrated with an inertial flight path marker and flight path reference cue to form guidance for the pilot where the integrated picture shows the current flight path and the aircraft position and their projection to the point of intended landing. This use of "scene-linked symbology" - where these symbolic references are located such that they overlay a real-world position and move and transform as though they were actual objects in the world - facilitates efficient cognitive processing and mitigates problems of attentional tunneling and symbology fixation. ${ }^{14,15}$

- The primary reference for maneuvering the airplane is based on what the pilot sees through the VS. As such, the required visual references must be continuously and distinctly visible and identifiable by the pilot.

- The only display element certified under the new $\S 91.175$ EFVS rule is a HUD but provisions for "an equivalent display" are also included. What constitutes an equivalent display is not defined, but the display must present "the required features and characteristics such that they are clearly visible to the pilot flying in his or her normal position and line of vision looking forward along the flight path."

Under $\$ 91.175(1)$, to operate below the $\mathrm{DA} / \mathrm{DH}$ or MDA, the visual references for the intended runway that must be distinctly visible and identifiable are shown in Table I for operation below the DA/DH or MDA and then, for operation below $100 \mathrm{ft}$ height above TDZE. 
Table I: Required Visual References per 14 CFR 91.175

\begin{tabular}{|c|c|}
\hline \multicolumn{2}{|c|}{ Required Visual References Using an Enhanced Flight Vision System (14 CFR $§ 91.175$ (I)) } \\
\hline 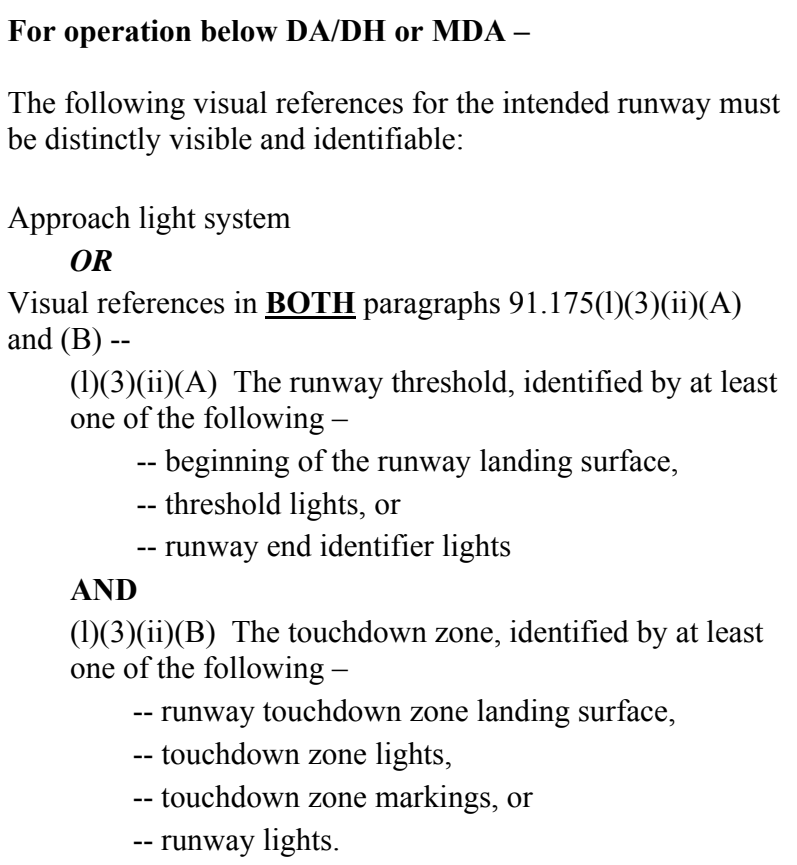 & $\begin{array}{l}\text { Descent below } 100 \text { feet height above TDZE - } \\
\text { The following visual references for the intended runway } \\
\text { must be distinctly visible and identifiable: } \\
\text { The lights or markings of the threshold } \\
\text { OR } \\
\text { The lights or markings of the touchdown zone }\end{array}$ \\
\hline
\end{tabular}

DO-315 establishes the minimum performance standards for an equivalent level of safety and performance to operate below the published DA/DH or MDA on a straight-in instrument approach procedure to $100 \mathrm{ft}$ height above TDZE. With the challenge of developing equivalent levels of performance and safety, the results of three recent human-in the-loop experiments are analyzed to start a performance-based requirements development and to identify what research needs to be conducted to extend beyond this current operation and allow the use EV and/or SV technology to land and roll-out in all-weather and visibility conditions.

\section{GUIDANCE MATERIAL}

AC120-29A documents an acceptable means for obtaining approval of operations in Category I/II landing weather minima (i.e., a DH lower than $200 \mathrm{ft}$ but not lower than $100 \mathrm{ft}$ and a runway visual range not less than $1200 \mathrm{ft}$ ). Part of the operation includes a "natural vision segment;" that is, below the DH, the primary reference for maneuvering the airplane is based on what the pilot sees visually.

AC120-28D describes an acceptable means for obtaining approval of operations in Category III landing weather minima (i.e., DHs below $100 \mathrm{ft}$, or no DH and a runway visual range not less than $700 \mathrm{ft}$ ). Unlike AC120-29A, AC120-28D does not include a natural visual segment. Consequently, with a goal of operating in Category III landing weather minima by use of SV and EV technology, a conundrum is created. Further operating credit for VS technology pushes into the AC120-28D weather and visibility arena but AC120-28D does not give consideration for a vision segment for the pilot.

New criteria for all-weather landing and roll-out operations are needed for VS technology. The corollary for this VS technology is that of a landing in Visual Meteorological Conditions, not of operating an auto-land system.

This paper evaluates previous experimental data for the goal of establishing the performance-based standards which may meet these goals. 
For this operation, the pilot/flight crew is assumed to be flying a straight-in instrument approach procedure with published vertical guidance. This assumption/restriction is imposed for three reasons. First, although truly "equivalent visual operations" are the ultimate objective of using this technology, the practicality is that initial work will open up lower landing minima for only a subset of operations; thus, only part of the complete EVO capability is explored for now. Second, safety of flight is improved using vertical descent guidance and must be promoted. The use of a continuous vertical descent trajectory fosters safe stabilized approach procedures. ${ }^{16}$ Also, using vertically guided approaches minimizes low altitude maneuvering since the intended landing runway and the intended touchdown aim point should be at the bottom of the approach and the VS technology should confirm that fact. Lastly, by using a straight-in approach with published vertical guidance, the design of the approach adheres to Terminal Instrument Procedures ${ }^{17}$ thus, obstacle clearance and obstacle protection is inherently provided. As such, the VS should not have to provide obstacle clearance/protection to enable lower landing weather minima.

At this time, a VS is not intended to change the roles and responsibilities of Air Navigation Services Providers for spacing and separation from other traffic. The VS is also not intended to change the roles and responsibilities of the airport services providers for foreign object damage control, wildlife control, or other airport infrastructure and service functions. Future growth and usage of VS technology may enable the flight crew to self-separate from other traffic, terrain, and obstacles.

Three experiments have recently been completed at NASA Langley Research Center (LaRC) evaluating certain aspects of EV and SV technologies to support NextGen all weather landing operations. The details of these experiments are not described herein but are referenced.

The three experiments were:

- Crew and Display Concepts Evaluation (CaD-CE) for Synthetic / Enhanced Vision ${ }^{18,19}$

- $\quad$ Synthetic Vision Systems - Operational Considerations (SVS-OC) ${ }^{12}$

- eXternal Visibility System (XVS)/All Weather Landing (AWxL) (XVS/AWxL) ${ }^{20,21}$

The objectives of these three experiments were not specifically targeted toward the development of performancebased all-weather landing requirements; but they do provide piece-wise information toward this goal. Just as importantly, their assumptions and limitations identify areas of future research, as discussed in the following.

\section{LANDING AND ROLL-OUT USING VISION SYSTEM TECHNOLOGY}

Below the DA/DH, the primary reference for maneuvering is based on what the pilot sees through the VS. What exactly is "seen," its performance, reliability and availability dictate the success of the operation.

\section{$\underline{4.1 \text { Visual References }}$}

To descend below the published DA/DH, the VS should display the required "equivalent visual" references continuously and distinctly visible and identifiable by the pilot. These visual references should be sufficient that they enable the pilot to manually fly the aircraft to (as per AC120-28D):

- "guide the airplane down the final approach segment to a touch down in the prescribed touch down zone"

- "with an appropriate sink rate and attitude without exceeding prescribed load limits of the airplane" and,

- " "rollout to converge on and track the runway centerline, from the point of touch down to a safe taxi speed."

A missed approach/go-around is executed if the required visual references are not continuously and distinctly visible and identifiable using the VS or if the aircraft is not in a position to land safely.

The required "equivalent visual" references for a VS landing can be assumed to be those of Table I which identifies the current-day natural visual references to successfully conduct this operation using natural vision.

\subsection{Head-Up Display Requirement}


From the FAA's perspective, the use of a HUD was an essential "characteristic and feature" of the EFVS operation. ${ }^{22}$ These "essential features" of the HUD or equivalent display were described as follows:

- The display should provide the EV image and spatially-referenced flight symbology so that they are aligned with and scaled to the external view (i.e., conformally drawn).

- The display should be located so the pilot is looking forward along the flight path (i.e., looking at and through the imagery to the out-of-the window view) to readily enable a transition from EFVS imagery to the out-the window view.

- The display should not require the pilot to scan up and down between a head down display of the image and the out-the-window view looking for primary flight reference information. This transition would otherwise be hindered by repeatedly re-focusing from one view to the other.

These HUD advantages are well founded in research. ${ }^{23-26}$ The HUD visual transition effects have even been shown in ground vehicle transportation studies. ${ }^{27}$ Superior lateral touchdown performance has also been shown using a head-up display than head-down displays for a transition to visual references, although no improvement in longitudinal touchdown performance was shown. ${ }^{30}$

The perceptual and cognitive issues associated with HUDs (e.g., attention capture) should not, however, be ignored. ${ }^{28,29}$ This issue was indirectly examined in the aforementioned NASA ground simulation tests. The Joint Aviation Authorities (JAA) Joint Aviation Requirement (JAR) All Weather Operations (AWO) performance-based approach standards were applied in an objective data analysisError! Reference source not found. ${ }^{17}$. Specifically, the AWO standards specify that no more than $5 \%$ of the approaches will have localizer deviations greater than $1 / 3$ dot or glideslope deviations greater than 1 dot between $300 \mathrm{ft}$ and $100 \mathrm{ft} \mathrm{HAT}$ for certification acceptance. These lowvisibility approach standards were not written specifically as quantitative performance standards for VS (e.g., $\mathrm{SV} / \mathrm{EV}$ ) operations, but were applied for comparative purposes.

The Continuous MethodError! Reference source not found.$^{17}$ technique was used to calculate the probability of success, $\mathrm{P}(\alpha)$, of meeting the AWO exceedance criteria ( $1 / 3$ dot localizer, 1 dot glideslope) with required levels of confidence for the HUD display concepts flown during the XVS/AWxL ${ }^{20,21}$ and $\mathrm{CaD}-\mathrm{CE}^{18,19}$ experiments.

The key differences pertinent to this analysis are that the CaD-CE experiment used a no-lower-than $100 \mathrm{ft}$ HAT transition to out-the-window visual references (following the $\$ 91.175(1)$ and $(\mathrm{m})$ EFVS operating rule) but the XVS/AWxL experiment did not include this natural vision transition. The XVS/AWxL test was flown with the forward view obstructed, by reference only to an EV image on the HUD. The side windows were unblocked and two conditions were experimentally varied: a) clear weather (i.e., peripheral vision cues); and b) $200 \mathrm{ft}$ runway visual range (i.e., no peripheral vision cues).

The probabilities of success for meeting the AWO localizer and glideslope criteria are shown in Table II, broken down by the visibility conditions. The analysis revealed that:

- $100 \%$ of the runs met the localizer criteria regardless of the visibility conditions.

- During the XVS/AWxL test (obstructed forward view), $78 \%$ of the runs with peripheral cues and $67 \%$ of the runs without peripheral cues met the glideslope criteria. Having peripheral cues in the side windows appears to have enabled slight improvement in glideslope tracking performance (78\% vs 67\%).

- In the CaD-CE experiment (with a visual transition no lower than $100 \mathrm{ft} \mathrm{HAT}$ ), glideslope tracking was worse than either XVS/AWxL condition. Although the flight crews and experiment protocols were different, the comparison of the two experiments suggests that a slight improvement in glideslope tracking $(60 \%$ vs. $67 \%)$ may be realized with elimination of the visual segment during landing.

The differences are not large and statistical significance for these differences cannot be determined. However, the trend makes intuitive sense. By allowing the pilot to concentrate on the task and display information, improved flight tracking performance results. The HUD-visual segment transition, although certainly improved over a headdown instrument to head-out visual transition, nonetheless, forces the pilots to simultaneously perform glideslope 
corrections and acquire the required landing visual references through normal vision.

The NASA ground simulations were conducted with a high fidelity, collimated out the-window visual simulation, but this attention switching/transition phenomena should be evaluated and verified in-flight.

Table II. Probabilities of Success in Meeting the AWO Localizer and Glideslope Criteria

\begin{tabular}{|c|c|c|c|c|}
\hline Experiment & Peripheral Cues & Localizer $\mathbf{P}(\boldsymbol{\alpha})$ & Glideslope $\mathbf{P}(\boldsymbol{\alpha})$ & Visual Landing Segment \\
\hline \hline XVS/AWxL & Yes & 100 & 78.2 & No \\
XVS/AWxL & No & 100 & 67.4 & No \\
\hline CaD-CE & Yes & 100 & 60.0 & Yes \\
\hline
\end{tabular}

\subsection{Field-of-View Criteria}

Because the VS operation is to mirror visual flight operations, one could argue that the cockpit window visibility required by the FARs, such as that defined under AC25-773 would establish the field-of-view requirement.

The overarching guidance within AC25-773 is that "the flight deck windshield must provide sufficient external vision to permit the pilot to safely perform any maneuvers within the operating limits of the aircraft." Two specific components are pertinent to the approach and landing phase.

A "clear vision field" is defined "to meet the most important objective ... provide optimum vision for avoidance of midair collisions in "see and be seen" conditions of flight." For an EVO capability, this "clear vision field" will form a critical requirement. However, for just landing operations, this "vision polar" might be excessive.

Two illustrations are shown as examples:

In Figure 1, the view forward of the pilot's eye point is drawn using elevation and azimuth angles from the aircraft body axis reference. A portion of the "clear vision field" directly forward of the pilot is shown. This figure also sketches a "best case" HUD, assuming a 24 deg V x 32 deg H HUD field-of-view, with the lowest extend of the HUD meeting the 17 deg clear vision nose-down requirement.

The HUD field-of-view does not cover the full extent of the "clear vision field." The question is whether this "clear vision field" is required just for "see and be seen" or if its full extent is also a requirement if we are only concerned with approach and landing operation.

Within the HUD field-of-view, this example shows what prominent runway features would be displayed if an EV system provided $2400 \mathrm{ft}$ visibility from a $100 \mathrm{ft}$ height above the TDZE point with the aircraft on a 3 degree glideslope to a $1000 \mathrm{ft}$ runway/glideslope intercept point without any crosswind. The illustration shows the symbolic horizon line, flight path marker and flight path reference symbol - all required references for an EFVS. Also displayed would be the last two light arrays of the Medium Intensity Approach Lighting System with Runway Alignment Indicator Lights (MALSR) (i.e., the red circles in Figure 1), the runway threshold lights (i.e., the green "plus" signs), and the runway edge lights at $200 \mathrm{ft}$ intervals (i.e., the black circles). A $2400 \mathrm{ft}$ EV range was assumed since it would be the minimum required EV visibility by rule to conduct an instrument approach to Category I minima. As this illustration shows, if these assumptions hold, the pilot should have a view of greater than the first $1400 \mathrm{ft}$ of the intended landing runway touchdown zone. 


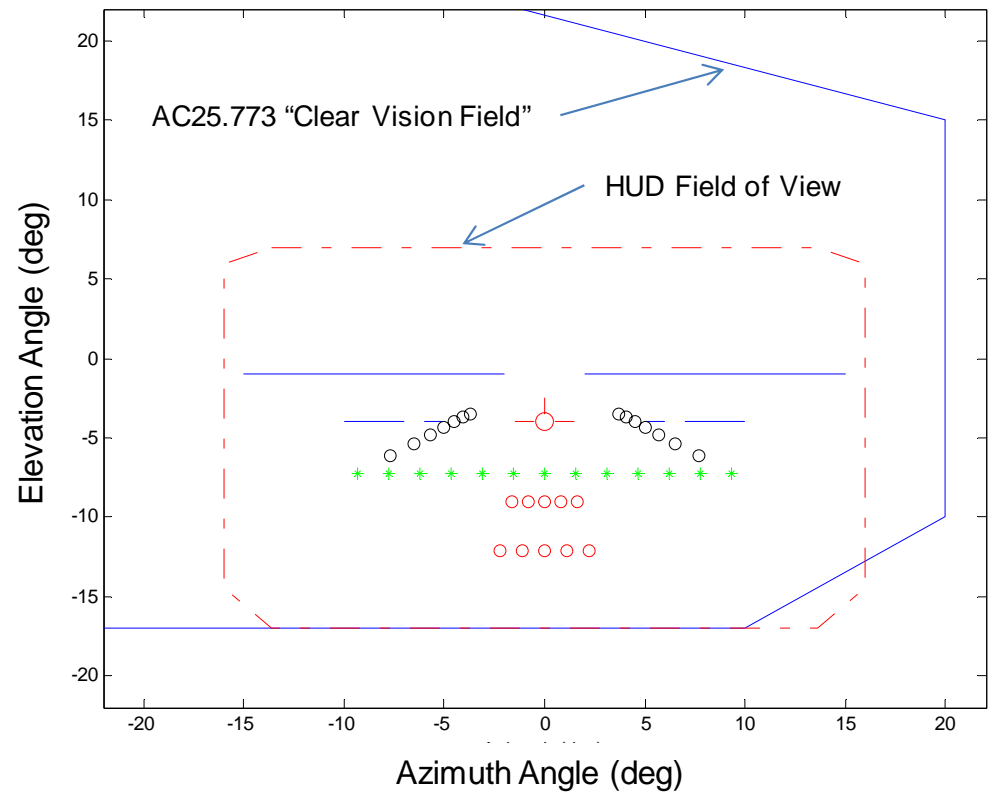

Figure 1: Illustration of Forward View from Aircraft with $2400 \mathrm{ft}$ Visibility in HUD

With the aircraft in the same position as Figure 1, this example is repeated but with only $1000 \mathrm{ft}$ visibility (see Figure 2). In this case, it is also assumed that this is the prevailing visibility available to the pilot-monitoring (PM) viewing the approach looking out the forward window (i.e., flight visibility using natural vision, not enhanced flight visibility using EFVS). This example shows that, with $1000 \mathrm{ft}$ visibility, the PM can see the last two arrays of the MALSR lights and the runway threshold lights. By the current $\$ 91.175(1)$ and $(\mathrm{m})$ EFVS rule, the required runway references, as per Table I (i.e., "the lights or markings of the threshold"), are visible using natural vision and the aircraft could proceed to landing.

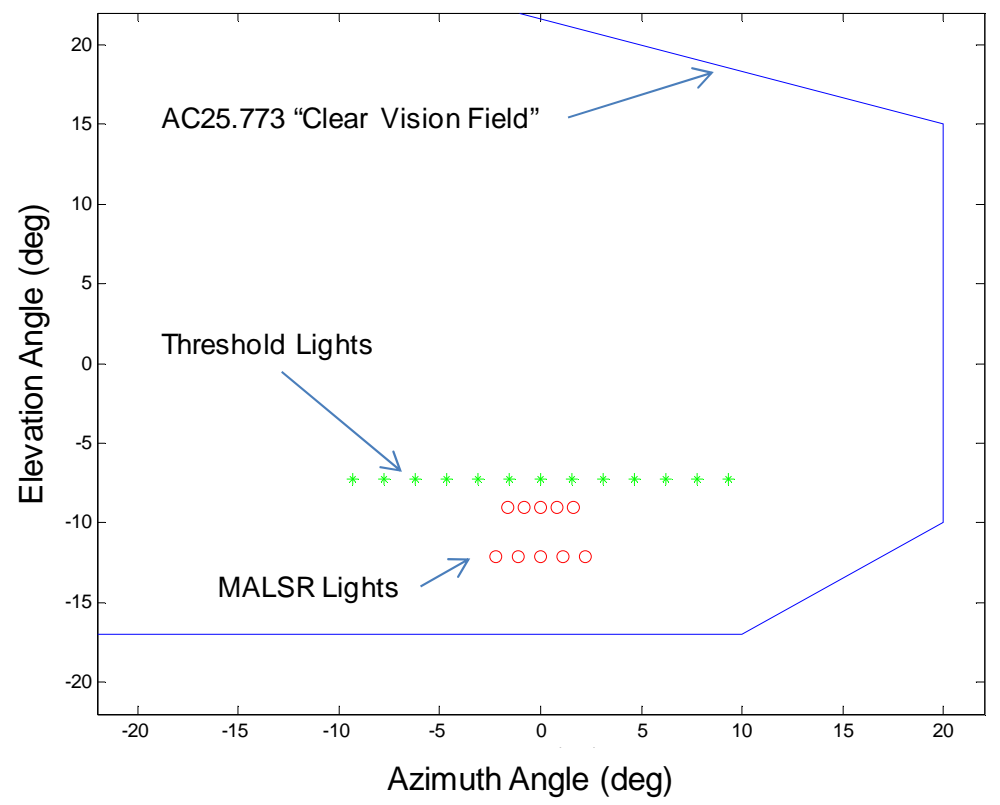

Figure 2: Illustration of Forward View from Aircraft with $1000 \mathrm{ft}$ Visibility 


\subsection{General Field-of-View Requirement}

As noted in the Airplane Flying Handbook ${ }^{31}$ "during the approach, round-out, and touchdown, vision is of prime importance." Research has attempted to quantify this but the exact visual mechanisms are many and varied. ${ }^{32}$

Depth perception is often cited as a factor in a successful flare, but research shows that binocular cues from stereopsis and vergence ${ }^{33}$ are of limited value in fixed-wing aircraft landing. Depth perception from monocular cues (e.g., perspective and occlusion) are more critical and are learned by pilots; thus, depth perception using the EV HUD conformal perspective presentation should not be significantly different than using the out-the-window view.

The ability of the pilot to successfully flare and touchdown is felt to be primarily dependent "on the angle at which the pilot's central vision intersects the ground (or runway) ahead and slightly to the side." ${ }^{\prime 31}$ The pilot is assumed to use such visual cues as changes in runway or terrain perspective. Yet research ${ }^{32}$ shows that "no clear research quantifying flow or classifying flow cues was found for aircraft landing."

The influence of visual cueing and reductions in field-of-view has been an active area of research since seemingly the dawn of aviation. ${ }^{34}$ Several studies were specifically conducted to address the feasibility and how much field-ofview is required to safely conduct approach and landing operations using video imagery. These studies showed that:

- Successful approaches could be performed and pilot performance was not adversely affected by field-of-view restriction down to $6^{\circ}$ horizontal $(\mathrm{H}) \times 30^{\circ}$ vertical $(\mathrm{V})$. The field-of-view restrictions were created by canopy masking. Touchdown performance was not significantly impacted by the field of view restrictions; however, pilot comments indicated that the task became increasingly difficult and the smoothness of longitudinal control inputs was reduced with decreasing field-of-view. ${ }^{35}$ With field-of-view restriction, pilots developed some "work-around" strategies to successfully fly with out-the-window-only information.

- Although pilots experienced some difficulty in flaring as accurately as desired, they were able to control a small aircraft through flare, landing, and roll-out using a 12 inch black-and-white monitor showing $21.5^{\circ} \mathrm{V}$ and $\mathrm{H}$ forward view. ${ }^{36}$ The primary difficulty reported was in estimating height during the last 10 feet from the runway. This difficulty was thought to be due partly to the narrow field-of-view, which limited the peripheral vision, but more strongly to the marginal resolution (only 7 to 11 arc minutes resolution) and depth of focus of the monitor.

- A DC-3 aircraft was flown comparing field-of-view and video imagery. Wide angle $\left(48^{\circ}\right)$, normal $\left(23^{\circ}\right)$, and telephoto $\left(11^{\circ}\right)$ fields-of-view which, respectively, resulted in angular magnifications of $0.34,0.73$, and 1.55 were flown using a monitor showing a subtended visual display angle of approximately $17 .^{037}$ These conditions were compared to flying with the pilot's outside vision restricted to only that seen through window masking providing approximately 20 degrees field-ofview. The data showed that it was possible to safely perform the landing task using the video displays, but the display minification/magnification had a significant effect. The restriction of vision to 20 degrees had very little effect on performance once the runway was in sight and the approach was initiated. In general, the pilots felt that this field-of-view provided essentially the same information as the normal full vision case.

While dated, these studies highlight three critical principles: 1) display resolution; 2) display minification; (e.g., conformality for equivalence to visual flight); and, c) field of view as small as $\sim 20^{\circ}$ being the "equivalent" to the unrestricted visibility condition if the image was collimated, conformal, and of eye-limiting resolution. Although not definitively concluded, these works support the DO-315 field-of-view requirement (i.e., $20^{\circ}$ ) and suggest that this minimum may be acceptable, but perhaps not sufficient field-of-view for all-weather landing.

\section{$\underline{4.5 \text { Flare Cue }}$}

A prominent concern for decreased horizontal field-of-view - although not necessarily supported by research - is that the lack of or restricted peripheral cues would adversely affect the pilot's sink rate judgment and flare control. This concern was addressed in the earliest days of HUD use in commercial applications by introduction of the flare cue. 
Some initial concern was that the flare cue might affect the normal perception and use of the visual landing cues but learning/training was expected to overcome any issues. ${ }^{38}$ Flight testing suggested that a flare cue was required, especially for wide runways using a millimeter wave radar imaging sensor, since the runway edgelines wouldn't subtend sufficient visual angles for sink rate perception and flare control. ${ }^{39}$ But a recent study investigating HUD all weather landing capability showed that the flare cue is unnecessary with an EV-equipped HUD since the pilots reported that they were "visual" using the EV imagery. The flare cue was ignored. ${ }^{40}$

The presence or absence of peripheral cues was investigated during the XVS/AWxL experiment. The primary purpose was to investigate the interaction of peripheral cues and collimated displays on landing using an XVS. In the full-factorial experiment design, this variation also tested the effect of peripheral cues on HUD landing, albeit without any forward out-the-window visual cues other than the EV HUD. ${ }^{20}$ The presence or absence of peripheral cues did not create any operationally significant differences in pilot workload or situation awareness in the flare and landing task. (Quantitative landing performance issues are discussed in Section 4.2).

The XVS/AWxL experiment used a flare cue. Unbeknownst to the pilots, annunciated and unannunciated failures of the flare cue occurred at $60 \mathrm{ft}$ and $35 \mathrm{ft}$ altitude, respectively, on one EV HUD run for four pilots. The runs were flown without peripheral cues. The EPs were trained on the display changes that occurred for the annunciated flare cue failure, but not for the unannunciated one.

The data showed that two of the four EPs verbally acknowledged the annunciated flare cue failure 3.25 and 8.25 second after the failures, respectively, and continued the approach and landed. The remaining two EPs did not explicitly mention the failure but continued the approach to a landing. All four landings were within the touchdown zone. In the case of the unannunciated failure, none of the four EPs explicitly acknowledged the failure and each continued to a landing. All unannunciated flare cue failure landings were within the touchdown zone.

These "non-normal" data suggest that the flare cue was not a powerful effect since 6 of 8 pilots didn't acknowledge a flare cue failure and performance degradation was not observed.

An important distinction to mention is that a flare cue is not flare "guidance." Under AC120-28D, criteria for a manual Category III HUD capability is described. Flare guidance is described as a HUD symbol which the pilot manually tracks to land the aircraft, in the absence of natural or EV visibility, within the AC120-28D required touchdown performance criteria. A flare cue, on the other hand, simply provides sink rate and altitude awareness analogous to a "rising runway" symbol, but does not provide specific direction to a touchdown landing zone.

\section{6 "3 Second" Rule for Field-of-View}

Item 4(d) within AC25-773 defines the "Landing Vision." This rule seemingly originates from a conference in $1963^{41}$ with refinement during development work on supersonic transports ${ }^{42}$ to establish the visibility requirements for approach and landing. This so-called 3 second rule is in addition to the clear vision area as follows:

"the view angle forward and down should be sufficient to allow the pilot to see a length of approach and/or touch-down zone lights that would be covered in three seconds at landing approach speed when the aircraft is:

(1) On a $21 / 2$ degree glideslope.

(2) At a decision height that places the lowest part of the aircraft at 100 feet above the touchdown zone extended horizontally.

(3) Yawing to the left to compensate for ten knots crosswind.

(4) Loaded to the most critical weight and center of gravity.

(5) Making the approach with 1200 feet runway visual range (RVR)."

The requirement is based on the perceived need of the flight crew/pilot to see some touchdown zone lighting for horizontal and vertical alignment for touchdown. For most aircraft, the 17 degree nose-low requirement contained in AC25-773 "clear vision area" supersedes this additional requirement. But for aircraft that fly at very high anglesof-attack like the Concorde, this requirement drives the design of the window and forward fuselage in the absence of another means of compliance, such as an XVS. 
This requirement was evaluated as part of the XVS/AWxL experiment by flying both high and low angle-of-attack conditions (without altering the handling characteristics). The data suggests that the 3 second rule, despite its dated heritage, is valid and should be met to provide landing line-up, control, and touchdown performance. ${ }^{12}$

\subsection{Landing Performance Criteria}

To begin the development of quantitative touchdown performance criteria, the NASA LaRC simulation data are examined. In each of the figures that follow, the "auto-land" quantitative performance criteria contained in AC12028D, Appendix 3 (200 to $2700 \mathrm{ft}$ longitudinal, $+/-58 \mathrm{ft}$ lateral for the B-757 aircraft, and $10 \mathrm{ftp}$ sink rate) are plotted for reference. (The side load and bank angle criteria of AC120-28D were not considered in this work.)

The CaD-CE experiment evaluated EFVS crew and display concept issues. From the CaD-CE experiment, the longitudinal landing distance from the threshold at touchdown is plotted in the top graph against the lateral distance from the centerline at touchdown and in the bottom graph against the sink rate at touchdown (T/D) in Figure 3. Only the nominal data are plotted (i.e., data from non-normal conditions are not plotted ${ }^{18,19}$ ). The pilot-flying (PF) used an EV HUD in low visibility conditions (approximately 1000 to $2400 \mathrm{ft} \mathrm{RVR}$ ) to manually land the simulated B-757 aircraft. An autothrottle was set to "speed-hold" on the approach speed at 138 knots indicated airspeed (KIAS), using $\mathrm{V}_{\text {ref }}+5$ for the simulated landing weight. The pilots were instructed to disengage the autothrottle for landing. The glideslope intercept was approximately $1000 \mathrm{ft}$ from the threshold of the 11,000 ft runway.
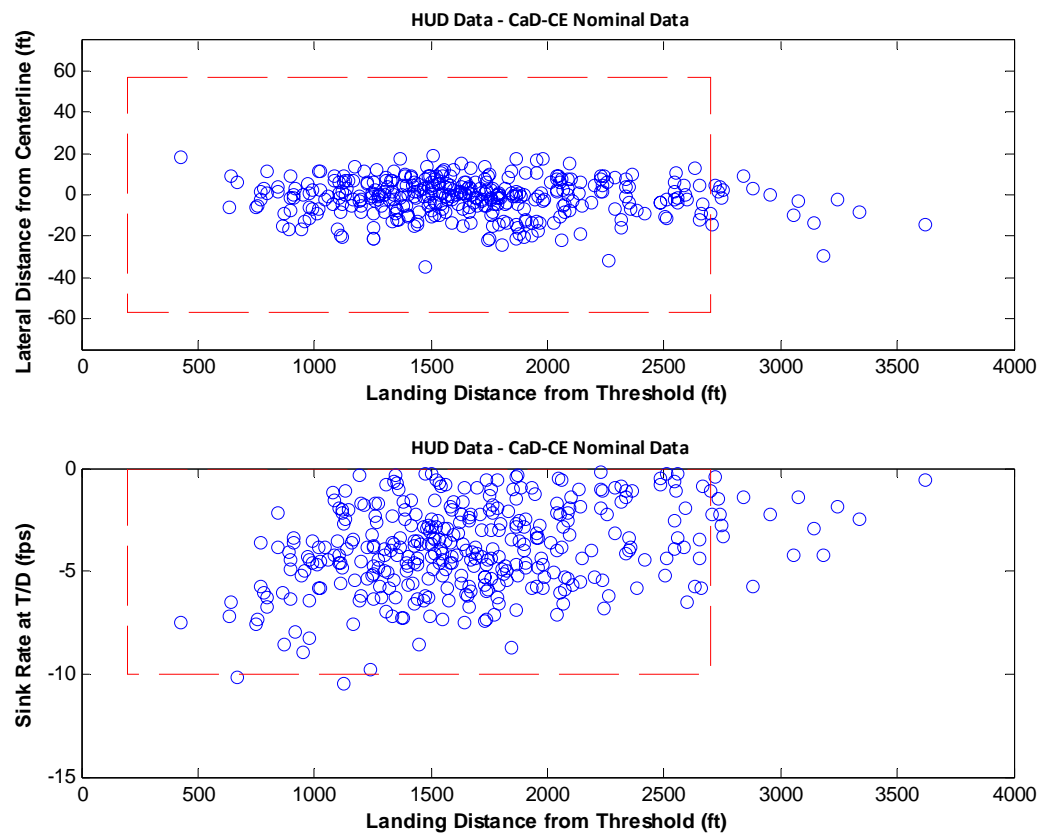

Figure 3: Lateral and Longitudinal Touchdown Distance and Sink Rate from CaD-CE Experiment

The XVS/AWxL experiment evaluated an EV HUD concept without any forward out-the-window visual cues other than the HUD, with and without peripheral cues from the side windows. From the XVS/AWxL experiment, the longitudinal landing distance from the threshold at touchdown and the lateral distance from the centerline at touchdown are plotted in Figure 4. In Figure 5, the longitudinal landing distance from the threshold and the sink rate at T/D are plotted. Only the nominal HUD data are plotted, with and without peripheral cues. The PF used an EFVS HUD showing approximately $4800 \mathrm{ft}$ visibility with the forward view otherwise obscured to manually land the simulated B-757 aircraft. $^{20,21}$ An autothrottle was set to "speed-hold" at the approach speed of 132 KIAS, using $\mathrm{V}_{\text {ref }}+5$ for the simulated landing weight. The pilots were instructed to disengage the autothrottle for landing. The glideslope intercept was approximately $1000 \mathrm{ft}$ from the threshold of the 11,000 ft runway. 

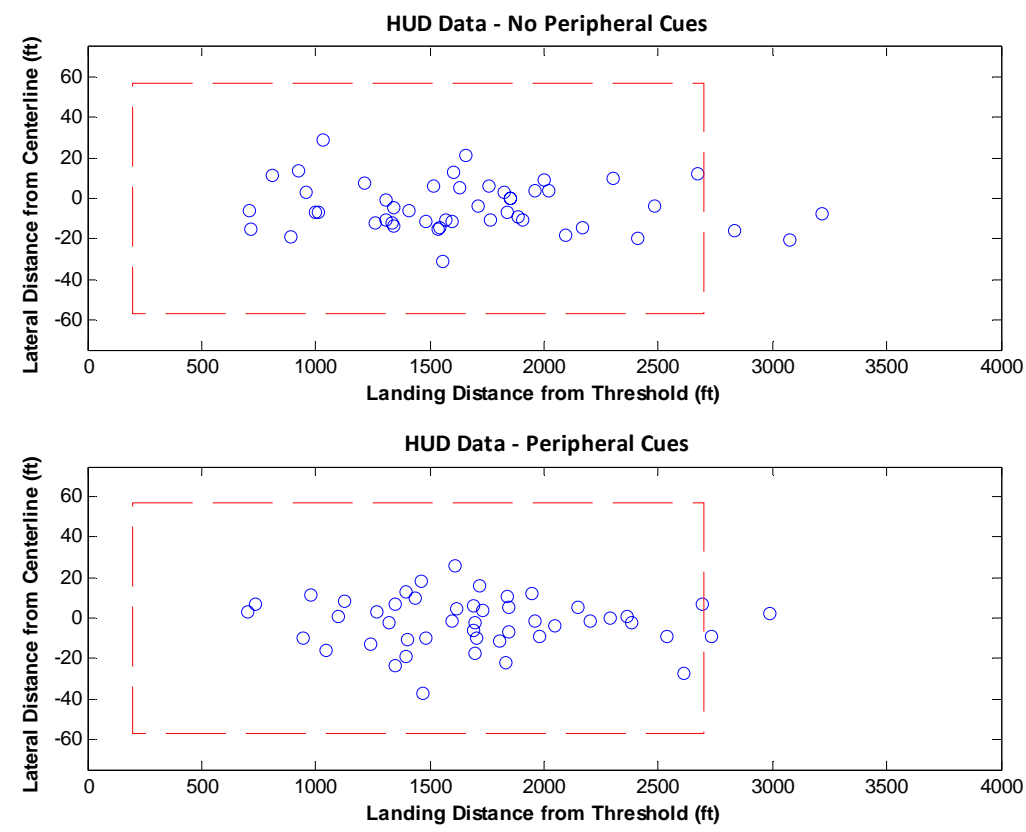

Figure 4: Lateral and Longitudinal Touchdown Distance from XVS/AWxL Experiment
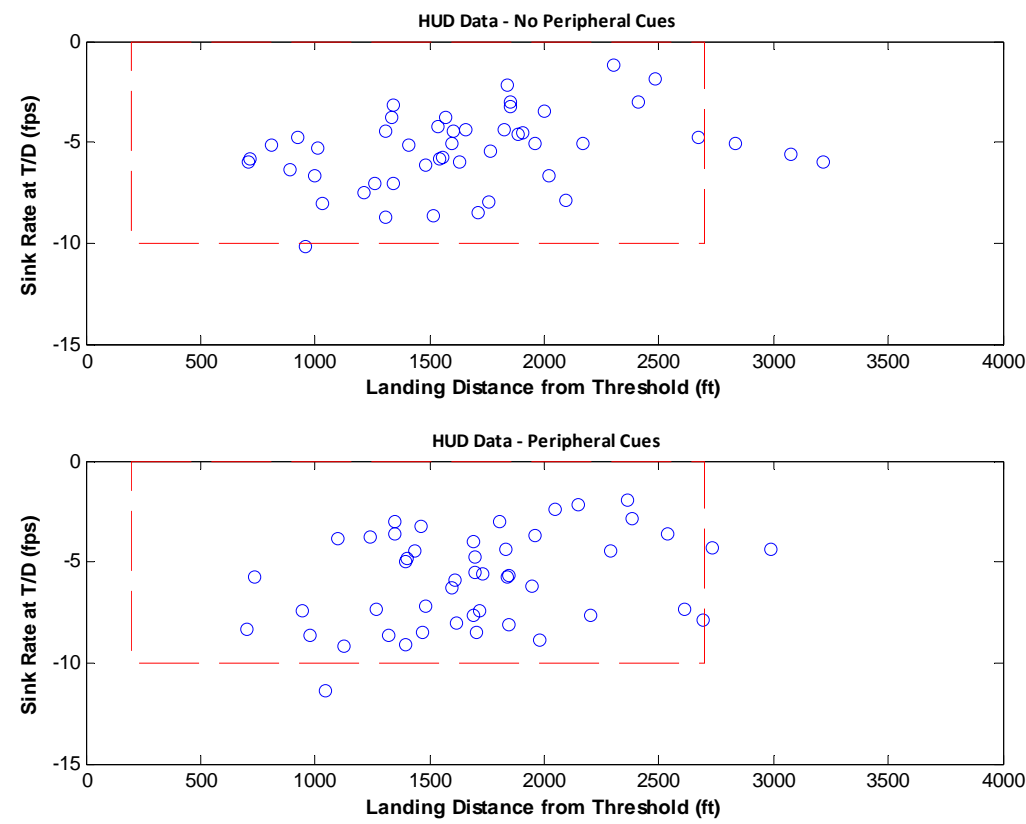

Figure 5: Sink Rate and Longitudinal Distance at Touchdown from XVS/AWxL Experiment

The SVS-OC experiment evaluated the potential for head-up and head-down SV concepts to support low visibility approach and landing operations. Below the $\mathrm{DA} / \mathrm{DH}$, the pilots were flying visually, without aiding from SV imagery. As such, selected data are used from this experiment to create a baseline comparison to manually landing a B-757 aircraft in ground simulation by use of HUD symbolic information alone. In Figure 6, the longitudinal landing distance from the threshold at touchdown is plotted in the top graph against the lateral distance from the 
centerline at touchdown and in the bottom graph against the sink rate at T/D. Only those configurations using the HUD and with a combination of approach and runway lighting and visibility that is operationally certified were used. From this experiment, these combinations were $3 \mathrm{~nm}$ visibility with minimum lighting, $2400 \mathrm{RVR}$ with MALSR lights, and 1200 RVR and 2400 RVR with ALSF-2 lighting. ${ }^{12}$ Only nominal data are shown. The PF manually landed the simulated B-757 aircraft following an instrument approach using SV on a HUD to a $100 \mathrm{ft}$ or $200 \mathrm{ft}$ DA/DH. An autothrottle was set to "speed-hold" at the approach speed of $138 \mathrm{KIAS}$, using $\mathrm{V}_{\text {ref }}+5$ for the landing weight of the simulated B-757 aircraft. The pilots were instructed to disengage the autothrottle for landing. The glideslope intercept was approximately $1000 \mathrm{ft}$ from the threshold of the 11,388 $\mathrm{ft}$ runway.
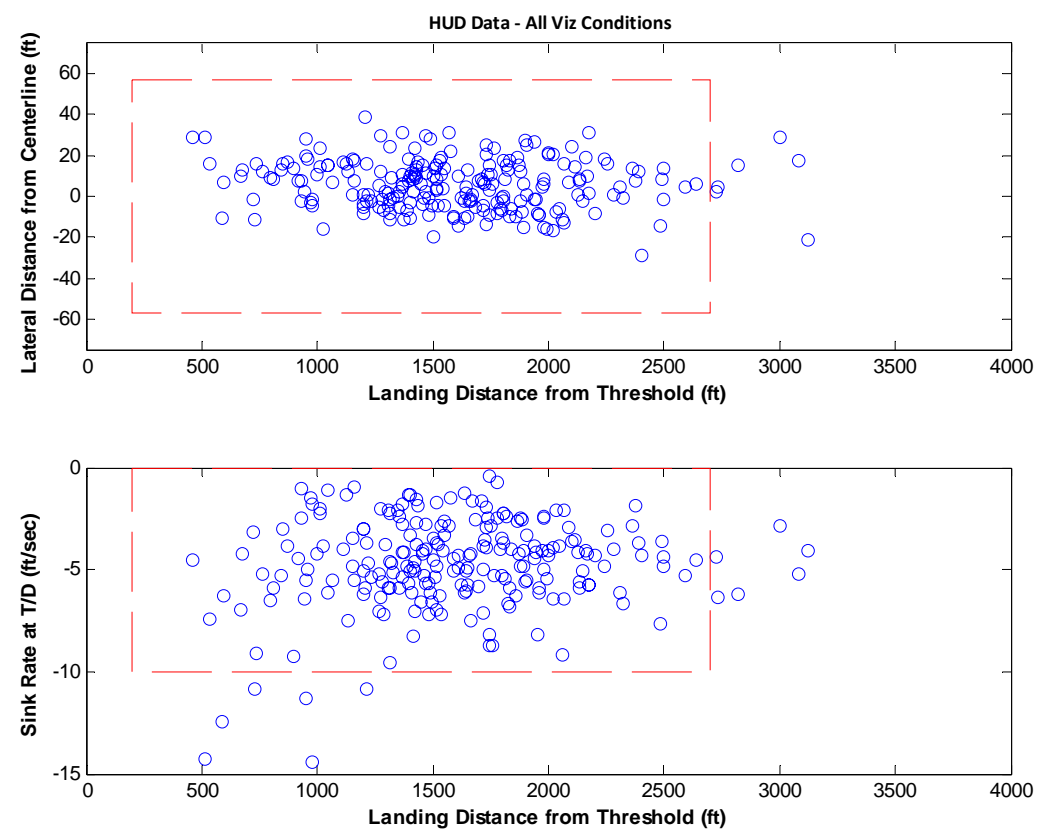

Figure 6: Lateral and Longitudinal Touchdown Distance and Sink Rate from SVS-OC Experiment

The mean, standard deviation, maximum, and minimum values for these data are tabulated in Tables III through V.

Table III: CaD-CE Touchdown Performance Statistics

\begin{tabular}{|l|c|c|c|}
\hline & $\begin{array}{c}\text { T/D Longitudinal } \\
\text { Position (ft) }\end{array}$ & $\begin{array}{c}\text { T/D Lateral } \\
\text { Position (ft) }\end{array}$ & $\begin{array}{c}\text { T/D Sink Rate } \\
\text { (ft/sec) }\end{array}$ \\
\hline \hline Mean & 1679.0 & -1.3 & -3.9 \\
\hline Standard Dev. & 531.5 & 8.9 & 2.1 \\
\hline Max. Value & 3618.0 & 19.0 & -0.1 \\
\hline Min. Value & 430.0 & -35.0 & -10.0 \\
\hline
\end{tabular}

The data show several interesting trends.

In all tests, the pilots were instructed to fly as if they were carrying passengers in Part 121 operations. All flight crew/pilots were Air Transport Pilot (ATP)-rated, employed by a Part 121 US carrier. The data show that with an EV HUD system or a visual landing with a HUD, none of the landings were short of the AC120-28D landing performance criteria, all were within the lateral criteria, and the majority of the landings were contained within the longitudinal criteria. But some landed long. An important aspect of the AC120-28D criteria, is that these 
performance bounds are to be met to a $10^{-6}$ probability level. None of the experiments met the AC120-28D criteria for lateral and longitudinal position at touchdown, but the lateral performance criteria is very close.

Table IV: XVS/AWxL Touchdown Performance Statistics

\begin{tabular}{|c|c|c|c|c|c|c|}
\hline & \multicolumn{2}{|c|}{ T/D Longitudinal Position (ft) } & \multicolumn{2}{|c|}{ T/D Lateral Position (ft) } & \multicolumn{2}{|c|}{ T/D Sink Rate (ft/sec) } \\
\hline & Peripheral Cues & $\begin{array}{c}\text { No } \\
\text { Peripheral Cues }\end{array}$ & Peripheral Cues & $\begin{array}{c}\text { No } \\
\text { Peripheral Cues }\end{array}$ & Peripheral Cues & $\begin{array}{c}\text { No } \\
\text { Peripheral Cues }\end{array}$ \\
\hline Mean & 1708.4 & 1664.1 & -2.1 & -4.0 & -5.9 & -5.4 \\
\hline Standard Dev. & 522.5 & 584.1 & 12.5 & 12.0 & 2.3 & 1.9 \\
\hline Max. Value & 2987.2 & 3216.8 & 26.0 & 29.3 & -1.9 & -1.2 \\
\hline Min. Value & 700.6 & 706.1 & -37.3 & -30.8 & -11.4 & -10.1 \\
\hline
\end{tabular}

Analysis of the sink rate data against the AC120-28D requirements has not yet been conducted but cursory examination suggests that this manual landing performance will not meet an auto-land performance criteria either. Experience in ground simulation suggests that sink rate control, in particular, is significantly degraded over actual flight performance. In flight, sink rate is much better controlled, whereas, in simulation, higher sink rates are experienced. ${ }^{43}$ This observation needs to be substantiated with HUD VS operations.

Table V: SVS-OC Touchdown Performance Statistics

\begin{tabular}{|l|c|c|c|}
\hline & $\begin{array}{c}\text { T/D Longitudinal } \\
\text { Position (ft) }\end{array}$ & $\begin{array}{c}\text { T/D Lateral } \\
\text { Position (ft) }\end{array}$ & $\begin{array}{c}\text { T/D Sink Rate } \\
\text { (ft/sec) }\end{array}$ \\
\hline \hline Mean & 1595.6. & 5.7 & -4.7 \\
\hline Standard Dev. & 494.1 & 12.1 & 2.23 \\
\hline Max. Value & 3123. & 39. & -0.4 \\
\hline Min. Value & 462. & -29. & -14.4 \\
\hline
\end{tabular}

To meet the AC120-28D longitudinal and lateral criteria, assuming normally distributed data, requires a mean touchdown longitudinal position of $1450 \mathrm{ft}$ and a standard deviation of $256 \mathrm{ft}$ and a zero mean for lateral position from centerline and a standard deviation of $12 \mathrm{ft}$, respectively. The data shown in Tables III-V indicate that the standard deviation data for lateral position very nearly meets the auto-land standard, but the longitudinal touchdown position data shows a mean distance farther past the threshold and with a higher standard deviation. (Note that the SVS-OC and XVS/AWxL longitudinal and lateral touchdown data met tests for normally distributed data; the CaD$\mathrm{CE}$ longitudinal and lateral touchdown data were slightly skewed from a normal distribution.)

The data suggests that manual control of an aircraft to touchdown cannot be performed as precisely as automation. This result is neither surprising nor is it unexpected. Research has shown time-and-time again, that while human performance can at times meet and exceed the performance of automation, automation provides better performance over the long run since it doesn't fatigue, lose focus and attention, or need to sleep or eat. But, more importantly, the human operator employs the most adaptive controller ever invented, which can cope with ever-changing, unexpected, or unique circumstances under which automation might, otherwise, catastrophically fail.

One might argue that if VS technology is not held to the AC120-28D performance requirements, safety might be compromised. A study was conducted to evaluate the feasibility of determining the relative differences in touchdown sink rate statistics between manual and automatic landings for the purposes of structural maintenance. ${ }^{44}$ Data measured on in-service Airbus 320 aircraft under the Airborne Data Monitoring Systems were analyzed. The T/D sink rates were less for manually flown landings than for autoland conditions. It was felt that pilots tried to minimize the sink rates for passenger comfort. 
More interesting is the fact that of the 15,047 landings recorded for this study, only 123 were automatic. Less than $1 \%$ of the landings were flown with an autoland system. While this statistic reflects of the relative lack of Category II/III weather requiring an autoland, it is also indicative of the ability of airline pilots to safely hand-fly an aircraft to landing. The outstanding Part 121 safety record is clearly borne out by this manual landing performance. So while the safety record of an autoland system cannot be discredited, the performance of manual flight is unrivaled and performance criteria based on manual control is safe and appropriate for performance-based VS technologies.

\section{$\underline{4.8 \text { Longitudinal Touchdown Performance Requirements for Vision System Technology }}$}

The implication for performance-based requirements development is that existing Category III auto-land requirements are neither relevant nor applicable to VS technology. This is not to say that landing performance isn't important. But the precision and repeatability of the autoland for touchdown performance isn't necessary since the human pilot can consider numerous factors into the landing - such as passenger comfort and runway conditions - to execute safe landings. The pilot can also monitor for a bad approach, given sufficient cues, and go-around, unlike an autoland. In fact, the FARs specifically call out that an appropriate missed approach procedure should be immediately executed if the pilot were unable to control the descent rate of the aircraft to allow touchdown to occur within the touchdown zone (TDZ) of the intended landing runway.

The TDZ is defined as the first $3000 \mathrm{ft}$ or the first third of the runway, whichever is more restrictive. The longitudinal touchdown data from the three NASA ground simulation experiments show that all touchdowns were within this TDZ requirement, except for 11 out of 678 landings - less than $2 \%$ of the landings.

There are four confounds or caveats in applying these data for substantiation of "true" VS performance:

1. Not all of the subject pilots were trained in flying a Boeing 757 aircraft. The subject pilot recruitment criteria was principally their experience in HUD operations and their status - holding an ATP rating with a US air carrier, not their aircraft type rating.

2. Very high approach speeds were flown, with a simulated B-757 aircraft near its maximum landing weight.

3. The pilots were not briefed specifically that they must adhere to the TDZ landing requirement as specified within the CFRs. This requirement was implied.

4. All approaches were manually flown and the autothrottles were set to speed hold. Because of aircraft experience and training differences, not all pilots were familiar with the operation of the simulator's autothrottle speed hold function and the fact that they had to manually disconnect the autothrottles and pull back the throttles to flight idle for good flare performance. In many instances, the pilots forgot to disconnect the autothrottles and the speed didn't bleed off, resulting in a floating tendency.

Two alternative requirements are evaluated as potential longitudinal touchdown performance criteria for VS technology.

In the first alternative, the capability for a go-around by the pilot in the event that they were unable to control the descent rate of the aircraft to allow touchdown to occur within the TDZ of the intended landing runway is accepted. Under the JAR AWO requirements, a go-around rate below $500 \mathrm{ft}$ attributable to the landing system performance or reliability may not be greater than $5 \%$. This requirement is primarily based on the implications of air traffic management in handling a large number of aircraft going missed. Instead, it's assumed that the go-around rate attributable to the VS should meet and exceed this requirement, but by an order of magnitude. A proposed alternative could be that no more than 5 in 1000 VS landings should result in a go-around. The alternative criterion would be that the landing system performance should demonstrate:

1. a longitudinal touchdown earlier than a point on the runway $0 \mathrm{ft}$. from the threshold to a probability of $5 \mathrm{x}$ $10^{-3}$; and,

2. a longitudinal touchdown beyond $3000 \mathrm{ft}$. from threshold to a probability of $5 \times 10^{-3}$; 
This proposed requirement could be met, if the mean T/D point were $1500 \mathrm{ft}$ from the threshold, with a standard deviation of no more than $534 \mathrm{ft}$ (assuming normally distributed data). This distribution of T/D position looks like a more reasonable approximation to that observed in the NASA simulation tests for manual control of landings (Tables III-V). Applying the touchdown data from the three NASA experiments to this alternative criteria shows that the SVS-OC data would meet this alternative criterion, but the XVS/AWxL and CaD-CE experiment data fall slightly outside.

Another concept for a performance-based touchdown criteria is proposed from aircraft developmental and certification flight testing procedures. In AC25-7, the procedures for determining an aircraft's landing distance are described. The landing distance is the horizontal distance from the point at which the main gear of the airplane is 50 $\mathrm{ft}$ above the landing surface (treated as a horizontal plane through the touchdown point) to the point at which the airplane is brought to a stop. The distance is treated in two parts of which the "air distance" - the distance from a height of $50 \mathrm{ft}$ to touchdown - is of interest. Several methods are proposed for determining the "air distance." The $\mathrm{AC}$ indicates that 40 landings usually establish satisfactory confidence levels for the data. This landing distance is used in the Aircraft Flight Manual for landing performance data.

The air distance data from the three NASA experiments is shown in Table VI. The data show that the air distance exhibits much less scatter than landing distance (as measured by the standard deviation). The air distance numbers reflect the pilot's ability to control the airspeed, its bleed-off, and flare the aircraft to touchdown with an acceptable sink rate. The longitudinal landing position values include these factors as well as introduces an additional variability from the imprecision of pilot control to precisely crossover the threshold at the designated threshold crossing height (TCH). The "rule-of-thumb" (e.g., see AC91-79, "Runway Overrun Protection") is that $200 \mathrm{ft}$ of additional landing distance results from every 10 feet above the TCH. The landing distance performance requirements are mostly influenced by precise control of the TCH and speed performance at the TCH and through the flare. ${ }^{45-47}$ These factors, unfortunately, were not controlled variables in the NASA experiments and additional testing is warranted to assess their influence in VS technology.

Table VI: Air Distance Statistics

\begin{tabular}{|l|c|c|c|c|}
\hline & $\begin{array}{c}\text { CaD-CE } \\
\text { Experiment }\end{array}$ & \multicolumn{2}{|c|}{ XVS/AWxL Experiment } & $\begin{array}{c}\text { SVS-OC } \\
\text { Experiment }\end{array}$ \\
& Peripheral Cues & Peripheral Cues & \\
\hline \hline Mean & 2814.1 & 1750.2 & 1745.8 & 1658.1 \\
\hline Standard Dev. & 460.0 & 398.0 & 391.1 & 411.7 \\
\hline Max. Value & 4646.4 & 3076.4 & 2669.0 & 2873.4 \\
\hline Min. Value & 1846.5 & 1047.1 & 891.3 & 557.3 \\
\hline
\end{tabular}

\section{CONCLUDING REMARKS}

Recent research in S/EV technology is analyzed with respect to existing Category II/III performance and certification guidance. The goal is to start the development of performance-based vision systems technology requirements to support future all-weather operations and the NextGen goal of Equivalent Visual Operations. This work shows that existing criteria to operate in Category III weather and visibility are not directly applicable since, unlike today, the primary reference for maneuvering the airplane is based on what the pilot sees visually through the VS. New criteria are consequently needed.

Research indicates that a minimum HUD field-of-view of 20 degrees is roughly equivalent to normal, unobscured vision for the approach and landing task, if the conformal HUD information is of sufficient resolution and clarity. A flare cue is typically included with commercial HUD symbology but flare cue criticality has not been substantiated. Since an EFVS should provide sufficient forward vision, landing by use of the flight path marker and imagery should obviate the need for a flare cue. 
Pilot-in-the-loop ground simulation testing documents the expected landing system touchdown performance by use of VS technology. However, these data are colored by several factors which were immaterial to the primary goals of the experiments, but are germane to this performance-based requirements development. Possible criteria are discussed, but more importantly, the factors associated with landing system performance using automatic and manual landings are delineated. Additional work is needed to refine and validate performance-based VS requirements for all-weather landing, and the influence of factors associated with manual control for flare and landing.

\section{REFERENCES}

[1] Joint Planning and Development Office: Next generation air transportation system integrated plan: a functional outline. Washington, DC: Author. 2008.

[2] National Aeronautics and Space Administration. (n.d.): Aviation safety program/integrated intelligent flight deck technical plan summary. Retrieved October 3, 2007, from http://www.aeronautics.nasa.gov/nra_pdf/iifd_tech_plan_c1.pdf.

[3] Arthur, J.J., III, Prinzel, L.J., Kramer, L.J., Bailey, R.E., and Parrish, R. V.: CFIT prevention using synthetic vision. In Proceedings of SPIE, Enhanced and Synthetic Vision 2003, Volume 5018, April 2003, pp. 146-157.

[4] Schiefele, J., Howland, D., Maris, J., Pschierer, C., Wipplinger, P., and Meuter, M.: Human Factors Flight Trial Analysis for 3D SVS: Part II. In Proceedings of SPIE, Enhanced and Synthetic Vision 2005, Editor: Jacques G. Verly, Volume 5802, Paper 18, April 2005.

[5] Schnell, T., Theunissen, E., and Rademaker, R.: Human Factors Test \& Evaluation of an Integrated Synthetic Vision and Sensor-Based Flight Display System for Commercial and Military Applications. Paper presented at the NATO Research and Technology Organization, Human Factors and Medicine panel workshop entitled "Toward Recommended Methods for Testing and Evaluation of EV and E/SV-Based Visionic Devices”, Williamsburg, VA, USA, 26-27 April 2005.

[6] Kramer, L.J., Prinzel, L.J., Bailey, R.E., and Arthur, J.J.: Synthetic vision enhances situation awareness and RNP capabilities for terrain-challenged approaches. In Proceedings of the American Institute of Aeronautics and Astronautics Third Aviation Technology, Integration, and Operations Technical Forum, AIAA 2003-6814, 1-11, April 2003.

[7] French, G. and Schnell, T.: Terrain Awareness \& Pathway Guidance for Head-Up Displays (TAPGUIDE): A Simulator Study of Pilot Performance. Proceedings of 22nd IEEE/AIAA Digital Avionics Systems Conference, Oct. 2003.

[8] Lemos, K. and Schnell, T.: Synthetic Vision Systems: Human Performance Assessment of the Influence of Terrain Density and Texture. Proceedings of 22nd IEEE/AIAA Digital Avionics Systems Conference, October 2003.

[9] Schnell T., Kwon, Y., Merchant, S., Etherington, T., and Vogl, T.: Reduced Workload and Improved Situation Awareness in Flight Decks Equipped with Synthetic Vision Information System Displays. International Journal of Aviation Psychology, 2002.

[10] Alexander, A.L., Wickens, C.D., and Hardy, T.J.: Synthetic Vision Systems: The Effects of Guidance Symbology, Display Size, and Field of View. Human Factors: The Journal of the Human Factors and Ergonomics Society, Vol. 47, No. 4, 693-707.

[11] Kramer, L.J., Arthur, J.J., III, Bailey, R.E., and Prinzel, L.J., III.: Flight testing an integrated synthetic vision system. In Proceedings of SPIE, Enhanced and Synthetic Vision 2005, Volume 5802, 1-12.

[12] Kramer, L.J., Williams, S. P., and Bailey, R.E.: Simulation evaluation of synthetic vision as an enabling technology for equivalent visual operations. In Proceedings of SPIE Enhanced and Synthetic Vision Conference 2008, 6957, 69570K$1-69570 \mathrm{~K}-15$.

[13] Minimum Aviation System Performance Standards (MASPS) For Enhanced Vision Systems, Synthetic Vision Systems, Combined Vision Systems And Enhanced Flight Vision Systems. RTCA/DO-315, RTCA Inc. Washington, DC. Dec 2008.

[14] Foyle, D.C., McCann, R.S., and Shelden, S.G.: Attentional Issues With Superimposed Symbology: Formats For SceneLinked Displays. In R.S. Jensen \& L.A. Rakovan (Eds.), Proceedings of the 8th International Symposium on Aviation Psychology, Vol. 8, Columbus, OH: Ohio State University. 1995. pp. 98-103..

[15] Foyle, D.C., Andre, A.D., McCann, R.S., Wenzel, E., Begault, D. and Battiste, V.: Taxiway Navigation And Situation Awareness (T-NASA) System: Problem, Design Philosophy And Description Of An Integrated Display Suite For LowVisibility Airport Surface Operations. SAE Transactions: Journal of Aerospace. Vol. 105, 1996, p. 1411-1418.

[16] Flight Safety Foundation: ALAR - Approach and Landing Accident Reduction Tool Kit. Flight Safety Digest, AugustNov 2000. 
[17] Federal Aviation Administration: United States Standard for Terminal Instrument Procedures (TERPS). Department of Transportation, Federal Aviation Administration Order No. 8260.3B, Dec 2007.

[18] Bailey, R. E., Kramer, L.J., and Prinzel III, L.J.: Fusion of Synthetic and Enhanced Vision for All-Weather Commercial Aviation Operations, In NATO Human Factors and Medicine Symposium on Human Factors and Medical Aspects of Day/Night All Weather Operations: Current Issues and Future Challenges, Tech. Rep. No. NATO RTOHFM-141, Neuilly-sur-Seine, France, RTO, 2008. pp. 11-1-11-18.

[19] Bailey, R. E., Kramer, L.J., and Prinzel, L.J., III: Crew and display concepts evaluation for synthetic/enhanced vision systems. In Proceedings of SPIE, Enhanced and Synthetic Vision Conference 2006, 6226, 62260G.1-62260G.18. April 2006.

[20] Kramer, LJ., Williams, S.P., Wilz, S.J., and Arthur III, J.J.: Simulation evaluation of equivalent vision technologies for aerospace operations. In Proceedings of SPIE Enhanced and Synthetic Vision Conference 2009, Jacques G. Verly and Jeff J. Guell, Eds., Vol. 7328, April 2009.

[21] Kramer, L.J., Williams, S.P., Wilz, S.J., Arthur III, J.J., and Bailey, R.E. (2009). Evaluation Of Equivalent Vision Technologies For Supersonic Aircraft Operations. In Proceedings of Digital Avionics Systems Conference, 2009.

[22] Federal Aviation Administration. Enhanced Flight Vision Systems, Final Rule. Department Of Transportation, Federal Aviation Administration, Federal Register, Vol. 69, No. 6, 9 January 9, 2004

[23] Wickens, C. D. and Long, J. (1994). Conformal Symbology, Attention Shifts, And The Head-Up Display. In Proceedings of the Human Factors and Ergonomics Society 38th annual meeting. Santa Monica, CA. pp. 6-10.

[24] Lauber, J.K., Bray, R.S., Harrison, R.L., Hemingway, J.C., and Scott, B.C.: An Operational Evaluation Of Head-Up Displays For Civil Transport Aircraft. NASA TP-1815, Moffitt Field, CA: NASA Ames Research Center. 1982.

[25] Martin-Emerson, R. and Wickens, C.D. (1997). Superimposition, Symbology, Visual Attention And The Head-Up Display. Human Factors, 39, pp. 581-601.

[26] Newman, R. L. (1995). Head-Up Displays: Designing The Way Ahead. Aldershot, England: Ashgate.

[27] Liu, Y-C. and Wen, M-H.: Comparison Of Head-Up Display (HUD) Vs. Head-Down Display (HDD): Driving Performance Of Commercial Vehicle Operators In Taiwan. International Journal of Human-Computer Studies, Volume 61, Issue 5, November 2004, pp. 679-697

[28] Crawford, J. and Neal, A.: A Review of the Perceptual and Cognitive Issues Associated With the Use of Head-Up Displays in Commercial Aviation. The International Journal Of Aviation Psychology, Vol. 16, No. 1, 2006. pp. 1-19.

[29] Prinzel III, L.J.:. Head-Up Displays And Attention Capture. Technical Report. NASA TM-2004-213000. Hampton, VA: NASA Langley Research Center. 2004.

[30] Goteman, Ö., Smith, K., and Dekker, S.: HUD With a Velocity (Flight-Path) Vector Reduces Lateral Error During Landing in Restricted Visibility. The International Journal Of Aviation Psychology, Vol. 17, No. 1, 2007. pp. 91-108.

[31] Federal Aviation Administration, “Airplane Flying Handbook.” Department Of Transportation, Federal Aviation Administration, FAA-H-8083-3A, 2004.

[32] Entzinger, J.O. and Suzuki, S.: Visual Cues in Manual Landing of Airplanes. In the proceedings of the KSAS-JSASS Joint International Symposium of Aerospace Engineering. The Korean Society for Aeronautical and Space Sciences. Nov 2008. pp. 388-395

[33] Entzinger, J.O.: The Role of Binocular Cues in Human Pilot Landing Control. In the Proceedings of AIAC13, the Thirteenth Australian International Aerospace Congress, Paper \#480, March 2009.

[34] Roscoe, S.N. The Effects of Eliminating Binocular and Peripheral Monocular Visual Cues upon Airplane Pilot Performance in Landing. Journal of Applied Psychology, Vol. 32, No. 6. Dec. 1948, pp. 649-662..

[35] Perry, J.J., Dana, W.H., and Bacon, Jr. D.C., Flight Investigation Of The Landing Task In A Jet Trainer With Restricted Fields Of View. NASA TN D 4018, June 1967

[36] Reeder, J.P. and Kolnick, J.J.: A Brief Study of Closed-Circuit Television for Aircraft Landing. NASA TN D-2185, February 1964.

[37] Kibort, B.R. and Drinkwater, Ill, F.J.:: A Flight Study of Manual Blind Landing Performance Using Closed Circuit Television Displays. NASA TN D-2252, May 1964.

[38] Bray, R.S. and Scott, B.C.. A Head-up Display for Low Visibility Approach. Paper presented at the 19th AIAA Aerospace Sciences Meeting, Paper No. AIAA-81-0130, Jan. 1981.

[39] Miller, D.J., and Hoobler, M.A.. C-130 Autonomous Landing Guidance (ALG) System. US Air Force Flight Test Center Report No. AFFTC TR-99-16, Oct. 1999.

[40] French, G.A., Murphy, D.M., and Ercoline, W.R.: Flare Cue Symbology for Zero-Zero Weather Landing. Enhanced and Synthetic Vision 2006, Eds: Jacques G. Verly and Jeff J. Guell, Proceedings of SPIE, Vol. 6226, April 2006.

[41] International Air Transport Association. All Weather Landing and Take-off. 15th Annual Conference of the International Air Transport Association, Lucerne, Switzerland, 25 April 1963. 
[42] Maguder, W.M., Heirich, C.J., Hobert, W.E., Pray, J.B., Fish, E.L., and Livingston, R.F.: A Practical Way to Consider Approach and Landing Visibilty Requirements. The Society of Experimental Test Pilots Annual Symposium, 1966. pp. 6-21.

[43] Grantham, W.D.: Comparison Of Flying Qualities Derived From In-Flight And Ground-Based Simulators For A JetTransport Airplane For The Approach And Landing Pilot Tasks. NASA Langley Research Center, NSA TP-2962, 1989.

[44] Rustenburg, J.W., Tipps, D.O., and Skinn, D. A Comparison of Landing Parameters from Manual and Automatic Landings of Airbus A-320 Aircraft. University of Dayton Research Institute Technical Report UDR-TM-2001-00003, Nov. 2001.

[45] Lambregts, A.A. and Creedon, J.F.: Development And Flight Evaluation Of Automatic Flare Laws With Improved Touchdown Dispersion. Paper presented at the 1980 AIAA Guidance and Control Conference, AIAA Paper No. 19801757, Danvers, MA, August 11-13, 1980.

[46] Green, H.B.: Manual Cat IIIa with a HUD: Requirements and Testing. Paper presented at the 1988 Society of Experimental Test Pilot (SETP) Thirty-Second Annual Symposium, Beverly Hills, CA, October 1988.

[47] Lambregts, A.A. Avoiding the Pitfalls in Automatic Landing Control System Design. Paper presented at the 1982 AIAA Guidance and Control Conference, AIAA Paper No. 1982-1599, San Diego, CA, August 9-11, 1982. 